\title{
Type B Lactic Acidosis in a Patient with Gastric Adenocarcinoma and Extensive Hepatic Metastases
}

\author{
Jeffrey D. Krimmel ${ }^{\mathrm{a}} \quad$ Clifford D. Packer ${ }^{\mathrm{a}, \mathrm{b}}$ \\ ${ }^{a}$ Case Western Reserve University School of Medicine, and ${ }^{b}$ Department of Medicine, Louis Stokes Cleveland \\ Veterans Affairs Medical Center, Cleveland, Ohio, USA
}

\section{Key Words}

Type B lactic acidosis · Gastric adenocarcinoma · Liver metastases

\begin{abstract}
Objective: We report the second case of gastric adenocarcinoma associated with type B lactic acidosis. Clinical Presentation and Intervention: An 81-year-old man presenting with upper gastrointestinal bleeding was found to have an advanced gastric adenocarcinoma. He had persistently elevated serum lactate attributed to malignancy-associated type $B$ lactic acidosis as a diagnosis of exclusion. As he remained clinically stable with a near-normal $\mathrm{pH}$, his elevated lactate was not specifically treated. Conclusion: This patient had an unusual type B lactic acidosis associated with gastric cancer. In the absence of signs and symptoms of other etiologies of lactic acidosis, physicians should consider malignancy-associated type $B$ lactic acidosis.
\end{abstract}

(C) 2015 S. Karger AG, Basel

\section{Introduction}

Type B lactic acidosis is a rare complication of nonhematologic malignancies. We report the second case of gastric cancer associated with type $B$ lactic acidosis [1]. In the cancer patient, it is important to identify type B lactic acidosis, as it represents a life threatening and potentially treatable complication. Several treatment modalities, including bicarbonate infusion and thiamine supplementation, have been employed in such cases with varying success, but removal of the malignancy remains the gold standard therapy.

\section{Case Report}

An 81-year-old man with a medical history of chronic kidney disease secondary to hypertension (stage III/IV) and peptic ulcer disease presented with epigastric pain, a weight loss of 25 pounds over several months, melena for 2 weeks and hematemesis for 2 days. He had a remote history of alcohol abuse, but had remained abstinent for 4 decades. His medications included $20 \mathrm{mg}$ of omeprazole twice daily and $20 \mathrm{mg}$ of furosemide daily. He had no known allergies.

His vital signs on admission were temperature: $36.3^{\circ} \mathrm{C}$, heart rate: $90 \mathrm{bpm}$, respiratory rate: 20 breaths/min and blood pressure: 173/63 mm Hg. Physical examination findings included generalized jaundice and a distended abdomen tender to palpation in the right upper quadrant with no peritoneal signs. There was profound hepatomegaly without splenomegaly. A rectal examination revealed guaiac-positive melenic stools. No palmar erythema, spider angiomas, asterixis or fluid wave were appreciated. The patient was started on intravenous fluids and a pantoprazole drip, and he remained clinically stable for the 4-day hospital course.

Initial laboratory tests showed hemoglobin of $11.6 \mathrm{~g} / \mathrm{dl}$ (decreased from $13.6 \mathrm{~g} / \mathrm{dl} 1$ month previously), a white blood cell

\begin{tabular}{ll}
\hline KARGER 125\% & $\begin{array}{l}\text { (1) 2015 S. Karger AG, Basel } \\
\text { 1011-7571/15/0244-0391\$39.50/0 Openger }\end{array}$ \\
$\begin{array}{l}\text { E-Mail karger@karger.com } \\
\text { www.karger.com/mpp }\end{array}$ & $\begin{array}{l}\text { This is an Open Access article licensed under the terms of the } \\
\text { Creative Commons Attribution-NonCommercial 3.0 Un- } \\
\text { ported license (CC BY-NC) (www.karger.com/OA-license), } \\
\text { applicable to the online version of the article only. Distribu- } \\
\text { tion permitted for non-commercial purposes only. }\end{array}$
\end{tabular}

Jeffrey D. Krimmel

Case Western Reserve University School of Medicine c/o Office of Student Affairs, Robbins Bldg, E-421 10900 Euclid Ave, Cleveland, OH 44106 (USA)

E-Mail jdk130@ case.edu 

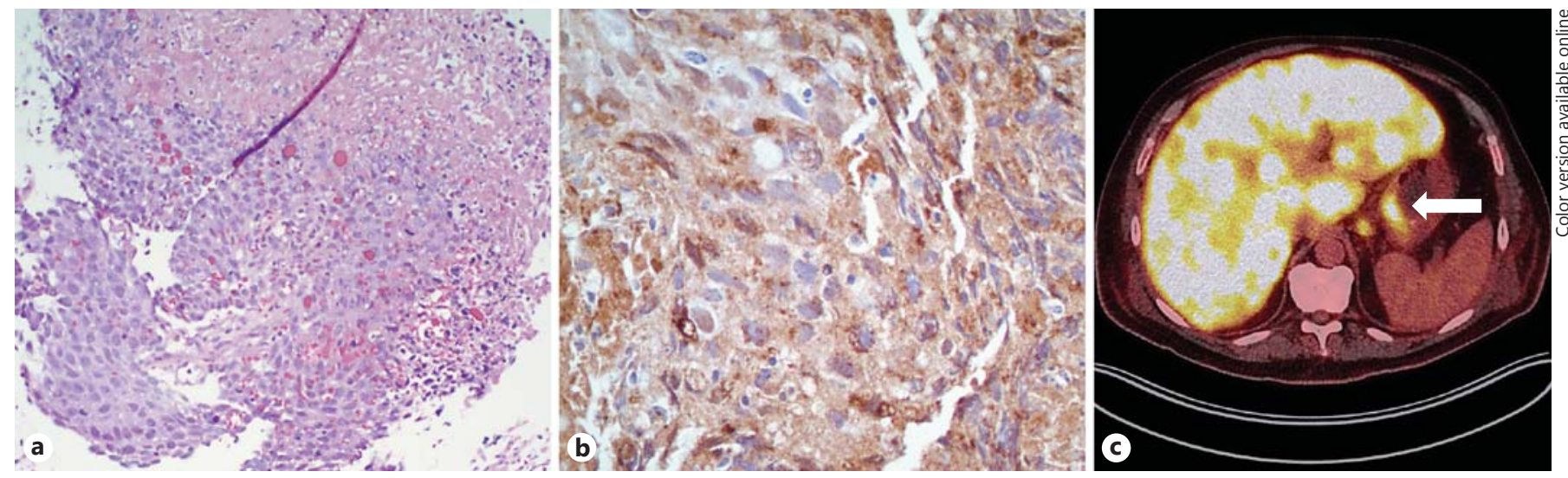

Fig. 1. Gastric tumor with extensive hepatic metastasis. a Histopathology demonstrates a poorly differentiated adenocarcinoma. HE stain. b Immunohistochemical staining demonstrates an AFP-positive adenocarcinoma (dark stain). c Abdominal positron emission tomography/computed tomography (transverse section). Diffuse hepatic disease and primary gastric tumor (arrow) demonstrate a fluorodeoxyglucose uptake signal.

count of $10.8 \times 10^{9}$ cells $/ 1$, a platelet count of $342 \times 10^{9} / 1$, total bilirubin of $10.1 \mathrm{mg} / \mathrm{dl}$, direct bilirubin of $6.1 \mathrm{mg} / \mathrm{dl}$, aspartate aminotransferase $727 \mathrm{U} / \mathrm{l}$, alanine aminotransferase $333 \mathrm{U} / \mathrm{l}$ and alkaline phosphatase $333 \mathrm{U} / \mathrm{l}$. Electrolytes revealed levels of sodium: $141 \mathrm{mEq} / \mathrm{l}$, potassium: $4.9 \mathrm{mEq} / \mathrm{l}$, chloride: $107 \mathrm{mEq} / \mathrm{l}$, bicarbonate: $16 \mathrm{mEq} / \mathrm{l}$, blood urea nitrogen: $68 \mathrm{mg} / \mathrm{dl}$, creatinine: $2.2 \mathrm{mg} /$ $\mathrm{dl}$, glucose: $81 \mathrm{mg} / \mathrm{dl}$, phosphorous: $6.0 \mathrm{mg} / \mathrm{dl}$ and calcium: $9.2 \mathrm{mg} /$ dl. Electrolytes showed no trend toward significant acute kidney injury or tumor lysis syndrome during the hospital course. Lactate was elevated at $6.6 \mathrm{mmol} / \mathrm{l}$. Urinalysis was unremarkable. P-lipase was normal. Urine drug screen, hepatitis panel and blood and urine cultures were negative. Arterial blood gas revealed two primary acid-base disorders: metabolic acidosis and respiratory alkalosis (pH: 7.43, $\mathrm{pCO}_{2}$ : $24.6 \mathrm{~mm} \mathrm{Hg}, \mathrm{pO}_{2}: 85.5 \mathrm{~mm} \mathrm{Hg}$ and $\left.\mathrm{HCO}_{3}^{-}: 16.1 \mathrm{mmol} / \mathrm{l}\right)$.

Diagnostic procedures included right upper quadrant abdominal ultrasound, which did not show common bile duct dilatation or gallstones. Esophagogastroduodenoscopy revealed a $2-\mathrm{cm}$, ulcerated mass on the retroflexion of the cardia. Biopsies of the mass revealed a poorly differentiated $\alpha$-fetoprotein (AFP)positive adenocarcinoma (fig. 1a, b). A diagnosis of gastric adenocarcinoma was made. Positron emission tomography/computed tomography showed uptake of fluorodeoxyglucose in the cardia of the stomach, diffuse and intense uptake in the liver and focal uptake in several pulmonary nodules and the pelvis (fig. 1c). Lactate remained persistently elevated throughout the hospital course (range 4.0-6.6 mmol/l). Tumor marker tests were significant for the levels of AFP (896 ng/ml, normal range: $0-8)$ and cancer antigen 19-9 $(100 \mathrm{U} / \mathrm{ml}$, normal range: $0-35)$. Due to the extent of his disease and his poor performance status, the patient was thought to be a poor candidate for antineoplastic intervention. The findings were discussed with the patient and his family, and he opted for discharge to hospice care. He died several days later.

\section{Discussion}

Our patient had persistent lactic acidosis over his 4-day hospital course, with lactate levels ranging from 4.0 to $6.6 \mathrm{mM}$, in the absence of hypotension or other clinical signs of ongoing end-organ dysfunction. This ruled out type A lactic acidosis (secondary to hypoperfusion). The absence of other reported etiologies of type B lactic acidosis, such as diabetes or active alcoholism [2], strongly supported a diagnosis of type B lactic acidosis secondary to malignancy.

A particularly unusual aspect of this case was the patient's initial arterial blood gas, as two primary acid-base disorders - an anion gap metabolic acidosis and a respiratory alkalosis - resulted in a near-normal pH. In such cases, patients usually present with severe systemic acidosis with high anion gaps and low carbon dioxide levels [1, $3,4]$. In this case, despite the significant lactic acidemia and increased anion gap, the patient's $\mathrm{pH}$ was borderline alkaline. By Winter's formula, the expected $\mathrm{pCO}_{2}$ was 30 $34 \mathrm{~mm} \mathrm{Hg}$ (actual $24.6 \mathrm{~mm} \mathrm{Hg}$ ). As there was no base excess, there was a concurrent primary respiratory alkalosis. This was most likely a central respiratory alkalosis from net-respiratory stimulatory substances (e.g. progesterone) that can accumulate in the setting of liver failure and/or from increased chemosensitivity to carbon dioxide [5].

There are several plausible pathophysiologic mechanisms for malignancy-associated type B lactic acidosis. (1) Malignancy can indirectly cause lactic acidosis by in- 
ducing thiamine deficiency, especially in the context of rapidly proliferating hematologic malignancies and total parenteral nutrition $[4,6]$. Thiamine is an essential cofactor for the pyruvate dehydrogenase complex, which converts pyruvate to acetyl-CoA and allows aerobic metabolism to proceed. In at least 1 case, thiamine supplementation was reported to improve lactic acidosis associated with an acute leukemia [6]. (2) Another hypothesis involves the Warburg effect - the tendency for tumor cells to favor glycolysis even in the presence of sufficient oxygen. It is thought that certain hematologic malignancies proliferate so rapidly that lactate production overwhelms the body's carbonic acid-bicarbonate buffer system $[6,7]$. An interesting component of this case was the AFP-positive tumor (fig. 1b), which is associated with aggressive tumor behavior [8]. Given the extensive tumor burden and aggressive tumor subtype, it is possible that the tumor's overwhelming anaerobic metabolism approximated that of a hematologic malignancy. (3) Reduced lactate clearance may be an important pathophysiologic factor, as was likely in our case. Normally, the liver is responsible for the clearance of $80-90 \%$ of lactate via the Cori cycle
[2], and extensive hepatic disease is therefore hypothesized to impact lactate metabolism. The kidney is responsible for clearing the remaining lactate. As this patient's serum lactate levels did not improve upon resolution of his mild acute kidney injury shortly after admission, it is possible that his baseline stage III/IV CKD may have contributed to the systemic lactate accumulation by impairing the secondary mechanism for lactate clearance.

\section{Conclusion}

This was a rare case of gastric carcinoma with extensive hepatic metastases causing a type B lactic acidosis. Physicians should be aware that type B lactic acidosis can occur in a variety of nonhematologic tumors, including gastric carcinoma.

\section{Acknowledgements}

The authors thank Dr. Prema Gogate for obtaining the pathology figures shown.

\section{References}

1 Permpalung N, Ammannagari N, Price CD et al: Refractory lactic acidosis in CD30 positive gastric cancer. Ann Hematol 2014;93: 1805-1806.

2 Emmet M: Causes of lactic acidosis; in Sterns RH, Forman JP (eds): UpToDate. Waltham, Wolters Kluwer, 2014.

3 Ruiz JP, Singh AK, Hart P: Type B lactic acidosis secondary to malignancy: case report, review of published cases, insights into pathogenesis, and prospects for therapy. ScientificWorldJournal 2011;11:1316-1324.
-4 Friedenberg AS, Brandoff DE, Schiffman FJ: Type B lactic acidosis as a severe complication in lymphoma and leukemia: a case series from a single institution and literature review. Medicine 2007;86:225-232.

5 Passino C, Giannoni A, Mannucci F, et al: Abnormal hyperventilation in patients with hepatic cirrhosis: role of enhanced chemosensitivity to carbon dioxide. Int J Cardiol 2012; 154:22-26.

6 Svahn J, Schiaffino M, Caruso U, et al: Severe lactic acidosis due to thiamine deficiency in a patient with B-cell leukemia/lymphoma on total parenteral nutrition during high-dose methotrexate therapy. J Pediatr Hematol Oncol 2003;25:965-968.

7 Silos EM, Shenep JL, Burghen GA, et al: Lactic acidosis: a metabolic complication of hematologic malignancies. Cancer 2001;92:22372246.

8 Liu X, Cheng Y, Sheng W, et al: Clinicopathologic features and prognostic factors in alphafetoprotein-producing gastric cancers: analysis of 104 cases. J Surg Oncol 2010;102:249-255. 